\title{
NGHIÊN CÚU ĐặC ĐIỂM LÂM SÀNG, CẬN LÂM SÀNG VÀ KẾT QUẢ PHẪU THUẬT PHỔI BIẸTT LẬP
}

\author{
Đinh Văn Lương ${ }^{*}$, Khiếu Mạnh Cuờng ${ }^{*}$, Đoàn Quốc Hung ${ }^{* *}$
}

\section{TÓM TÁ́T}

36 trường hợp (13 nam, 23 nữ) chẩn đoán phổi biệt lập sau phẫu thuật. Tuồi trung bình $33,19 \pm 13$ tuổi, 21 trường hợp có tiền sử điều trị các bệnh hô hấp khác nhau, triệu chứng lâm sàng chủ yếu đau ngực và ho, sốt, khó thở, XQ ngực thường quy chủ yếu với 3 dạng tổn thương: dạng u, kén khí, viêm. Chẩn đoán xác định dựa trên CT-Scanner ngực có dựng hình mạch máu phát hiện mạch bất thường từ hệ động mạch chủ cấp máu cho phần phổi tổn thương. Điều trị phẫu thuật chủ yếu cắt thùy phổi $34 / 36$ trường hợp, 1 trường hợp cắt phần phổi chứa phổi biệt lập, 1 trường hợp cắt phổi biệt lập, thời gian mổ trung bình $195,6 \pm 66$ phút. Biến chứng sau phẫu thuật 7 trường hợp đặc biệt có 1 trường hợp rò thực quản. Thời gian nằm viện sau mổ khi không có biến chứng trung bình $15,84 \pm 8.18$ ngày, không có tử vong trong và sau mổ.

\section{SUMMARY}

36 cases were performed an analysis: Sex rate: male/female 13/23. Age mean: $33,19 \pm 13$, min 11, max 62. Image in CT- Scanner: location of pulmonary sequestration: right /lef $13 / 23$ and all of them were in low lobe at both side with image as pulmonary emphycematous bullae15 case $(41,67 \%)$, Homogeneous shadow ( 9 case 25\%),pulmonary tumour (6 case $16,67 \%$ ), pulmonotis (6 case $16,67 \%$ ). Blood supply were aorta thoracica descendens (22/32 case) and aorta abdominalis (8/32case), arterial coeliaca(2/32 case). Preoperative diagnosis: Pulmonary sequestration 32/36 case. Surgical procedure in treatment Pulmonary sequestration: 34(94,44\%) lobectomy, 1(2,78\%) Segmental resectin, $1(2,78 \%)$ Cystectomy. There was a case fistula oesophageal in 7 case postoperative complication. Whithout complication, the mean postoperative hospital stay $15,84 \pm 8,18$ days.

\section{1. ĐĂT VẤN ĐỀ}

Khái niệm về phổi biệt lập: phổi biệt lập là dị tật bẩm sinh hiếm gặp ở phổi chiếm $0,15-6,4 \%$ các dị dạng ở phổi. Phần phổi này không thông thương với cây phế quản và được cấp máu từ đại tuần hoàn như động mạch chủ (ĐMC) ngực, ĐMC bụng, rất hiếm từ động mạch phổi. Phổi biệt lập có 2 loại: phổi biệt lập trong thùy $(>75 \%)$ có cùng màng phổi tạng với phần phổi còn lại, và phổi biệt lập ngoài thùy $(<25 \%)$ có màng phủ riêng biệt với phần phổi còn lại. Một số trường hợp có phối hợp với các dị tật đường tiêu hóa, cơ hoành, hệ xương... chẩn đoán dị tật này có thể từ rất sớm trước sinh (16-24 tuần thai) và được can thiệp sớm sau sinh. Năm 1777, Huber mô tả động mạch hệ thống lạc chỗ (aberrant) cấp máu cho phổi đi từ ĐMC ngực. Năm 1874 Klebs mô tả sự kết hợp của phổi biệt lập với một số dị dạng tiêu hóa. Đến năm 1946, Pryce - người đầu tiên mô tả đầy đủ và phân loại PBL trong và ngoài thùy. Ông dùng thuật ngữ biệt lập bắt nguồn từ tiếng Latin "sequestrare" có nghĩa là "riêng biệt". Ở Việt Nam, phổi biệt lập thường phát hiện chẩn đoán, điều trị muộn khi đã có biến chứng. Tại bệnh viện Phổi trung ương từ 2009-2014, chúng tôi hồi cứu các trường hợp được chẩn phổi biệt lập với 2 mục tiêu:

1. Mô tả một số đặc điểm lâm sàng và chẩn đoán hình ảnh phổi biệt lập.

2. Đánh giá kết quả sớm phẫu thuật bệnh nhân phổi biệt lập.

\section{2. ĐỐI TƯợNG VÀ PHƯơng PHÁP NGHIÊN CÚU}

\section{1. Đối tượng}

Đối tượng nghiên cứu những bệnh nhân được chẩn đoán là phổi biệt lập tại Bệnh viện Phổi trung ương từ tháng 1 năm 2009 đến tháng 12 năm 2014.

\subsubsection{Tiêu chuẩn lụa chọn}

- Bệnh nhân được chẩn đoán sau mổ là phổi biệt lập.

- Có kết quả giải phẫu bệnh sau mổ là phổi biệt lập.

- Mọi lứa tuổi, giới tính.

- Hồ sơ bệnh án của bệnh nhân đầy đủ thông tin.

\subsubsection{Tiêu chuẩn loại trù̀}

- Hồ sơ bệnh án không đủ tiêu chuẩn chẩn đoán phổi biệt lập sau mổ.

- Bệnh nhân được chẩn đoán phổi biệt lập nhưng không mổ.

- Bệnh nhân chẩn đoán trước mổ là phổi biệt lập nhưng sau mổ không phải là phổi biệt lập.

*Bệnh viện Phổi trung ương
** Bộ môn ngoại Truờng đại học Y Hà Nộ

Người chịu trách nhiệm khoa học: PGS.TS. Đoàn Quốc Hung

Ngày nhận bài: 20/07/2015 - Ngày Cho Phép Đăng: 20/08/2015

Phản Biện Khoa họ: PGS.TS. Đặng Ngocc Hùng

PGS.TS. Lê Ngọc Thành 


\subsection{Phương pháp nghiên cứu}

- Nghiên cứu mô tả, hồi cứu

- Lấy mẫu thuận tiện: tất cả các bệnh nhân có đủ tiêu chuẩn nghiên cứu.

\subsection{Phương pháp thu thập số liệu}

Khai thác thông tin hồ sơ bệnh án sẵn có điền vào

\section{KẾT QUẢ}

\subsection{Một số đặc điểm lâm sàng, cận lâm sàng của phổi biệt lập}

\subsubsection{Phân bố bệnh theo tuổi, giới}

36 bệnh nhân đủ tiêu chuẩn nghiên cứu gồm Nam 13, Nữ: 23. Tuổi thấp nhất:11,Tuổi cao nhất: 62, Tuổi trung bình: $33,19 \pm 13$ tuổi; nhóm $<=16$ tuổi: 2 trường hợp, nhóm $>16$ tuổi 34 trường hợp

\subsubsection{Tiền sử bệnh - Triệu chứng lâm sàng}

Bảng 3.1 Tiền sử các bệnh hô hấp, triệu chứng lâm sàng.

\begin{tabular}{|c|c|c|c|c|c|c|c|c|c|}
\hline Tiền sử & $\begin{array}{l}\text { Kén } \\
\text { phế } \\
\text { quản }\end{array}$ & $\begin{array}{l}\text { Viêm } \\
\text { phế } \\
\text { quản }\end{array}$ & $\begin{array}{l}\text { Viêm mủ } \\
\text { màng phổi }\end{array}$ & $\begin{array}{c}\text { Viêm hô } \\
\text { hấp tái } \\
\text { diễn }\end{array}$ & $\begin{array}{l}\text { Apxe } \\
\text { phổi }\end{array}$ & $\begin{array}{l}\text { Ho } \\
\text { máu }\end{array}$ & $\begin{array}{l}\text { Viêm } \\
\text { phổi }\end{array}$ & $\begin{array}{l}\text { Lao } \\
\text { phồi }\end{array}$ & $\begin{array}{c}\text { Giãn } \\
\text { phế } \\
\text { quản }\end{array}$ \\
\hline $\mathrm{n}$ & 1 & 2 & 2 & 4 & 4 & 2 & 7 & 5 & 3 \\
\hline$\%$ & 3,33 & 6,67 & 6,67 & 13,33 & 13,33 & 6,67 & 23,33 & 16,67 & 10 \\
\hline \multirow{3}{*}{$\begin{array}{l}\text { Triệu } \\
\text { chứng }\end{array}$} & & \multicolumn{2}{|c|}{ Đau ngực } & \multicolumn{2}{|c|}{ ho } & \multicolumn{2}{|c|}{ sốt } & \multicolumn{2}{|c|}{ khó thở } \\
\hline & $\mathrm{n}$ & \multicolumn{2}{|c|}{29} & \multicolumn{2}{|c|}{30} & \multicolumn{2}{|c|}{16} & \multicolumn{2}{|c|}{11} \\
\hline & $\%$ & \multicolumn{2}{|c|}{33,72} & \multicolumn{2}{|c|}{34,88} & \multicolumn{2}{|c|}{18,6} & \multicolumn{2}{|c|}{12,79} \\
\hline
\end{tabular}

\subsection{3. Đặc điểm chẩn đoán hình ảnh.}

Chụp XQ ngực thường quy: 3 dạng tổn thương tỷ lệ: dạng u:kén khí:viêm 10:15:11

phổi phải 13 trường hợp, phổi trái 23 trường hợp

Bảng 3.2. Đối chiếu hình ảnh CLVT với chẩn đoán sau mổ.

\begin{tabular}{|l|l|c|c|c|c|c|c|c|}
\hline \multicolumn{2}{|c|}{$\begin{array}{l}\text { CTL } \\
\text { PBL } \\
\text { sau mổ }\end{array}$} & $\begin{array}{c}\text { Dạng } \\
\text { u phổi }\end{array}$ & $\begin{array}{c}\text { Dạng } \\
\text { viêm }\end{array}$ & $\begin{array}{c}\text { Dạng kén } \\
\text { khí }\end{array}$ & $\begin{array}{c}\text { Dạng } \\
\text { nang dịch }\end{array}$ & $\begin{array}{c}\text { ĐMC } \\
\text { ngực }\end{array}$ & $\begin{array}{c}\text { ĐMC } \\
\text { bụng }\end{array}$ & $\begin{array}{c}\text { ĐM thân } \\
\text { tạng }\end{array}$ \\
\hline \multirow{2}{*}{ Trong thùy } & $\mathrm{n}$ & 6 & 6 & 14 & 8 & 20 & 8 & 2 \\
\cline { 2 - 10 } & $\%$ & 16,67 & 16,67 & 38,89 & 22,22 & 62,50 & 25 & 6,25 \\
\hline \multirow{2}{*}{ Ngoài thùy } & $\mathrm{n}$ & 0 & 0 & 1 & 1 & 2 & 0 & 0 \\
\cline { 2 - 10 } & $\%$ & 0 & 0 & 2,78 & 2,78 & 6,25 & 0 & 0 \\
\hline
\end{tabular}

\section{2. Điều trị phẫu thuật}

Bảng 3.3. Kỹ thuật, thời gian mổ, mạch bất thương trong mổ

\begin{tabular}{|c|l|c|c|c|c|c|c|}
\hline \multirow{2}{*}{ Đặc điểm } & \multicolumn{2}{c|}{ PBL trong thùy } & PBL ngoài thùy & \multicolumn{3}{c|}{ Chung } \\
\cline { 3 - 8 } & $\mathbf{n}$ & $\mathbf{\%}$ & $\mathbf{n}$ & $\mathbf{\%}$ & $\mathbf{n}$ & $\mathbf{\%}$ \\
\hline \multirow{3}{*}{ Kỹ thuật mổ ốn } & Cắt phần PBL & 0 & & 1 & 2,78 & 1 & 2,78 \\
\cline { 2 - 8 } & Cắt thùy phối & 33 & 91,66 & 1 & 2,78 & 34 & 94,44 \\
\cline { 2 - 7 } & Cắt phân thùy phổi & 1 & 2,78 & 0 & 0 & 1 & 2,78 \\
\hline
\end{tabular}

\begin{tabular}{|l|c|c|c|c|c|c|c|c|}
\hline $\begin{array}{l}\text { Kích thước động } \\
\text { mạch bất thường }\end{array}$ & $\mathrm{n}$ & $\begin{array}{c}\text { Tỷ lệ } \\
\%\end{array}$ & $\begin{array}{c}\text { Số lượng } \\
\text { mạch bất thường }\end{array}$ & $\mathrm{n}$ & $\begin{array}{c}\text { Tỷ lệ } \\
\%\end{array}$ & $\begin{array}{c}\text { Nguyên ủy bất } \\
\text { thường }\end{array}$ & $\mathrm{n}$ & $\begin{array}{c}\text { Tỷ lệ } \\
\%\end{array}$ \\
\hline Dưới $0,5 \mathrm{~cm}$ & 14 & 38,89 & 1 dộng mạch & 27 & 75 & Chủ ngực & 23 & 63,89 \\
\hline $0,5-1 \mathrm{~cm}$ & 19 & 52,78 & 2 dộng mạch & 4 & 11,11 & Chủ bụng & 12 & 33,33 \\
\hline $1-1,5 \mathrm{~cm}$ & 3 & 8,33 & > 2 động mạch & 5 & 13,89 & Ngục- bụng & 1 & 2,78 \\
\hline
\end{tabular}


Bảng 3. 4. Đối chiếu chẩn đoán trước mổ và sau mổ.

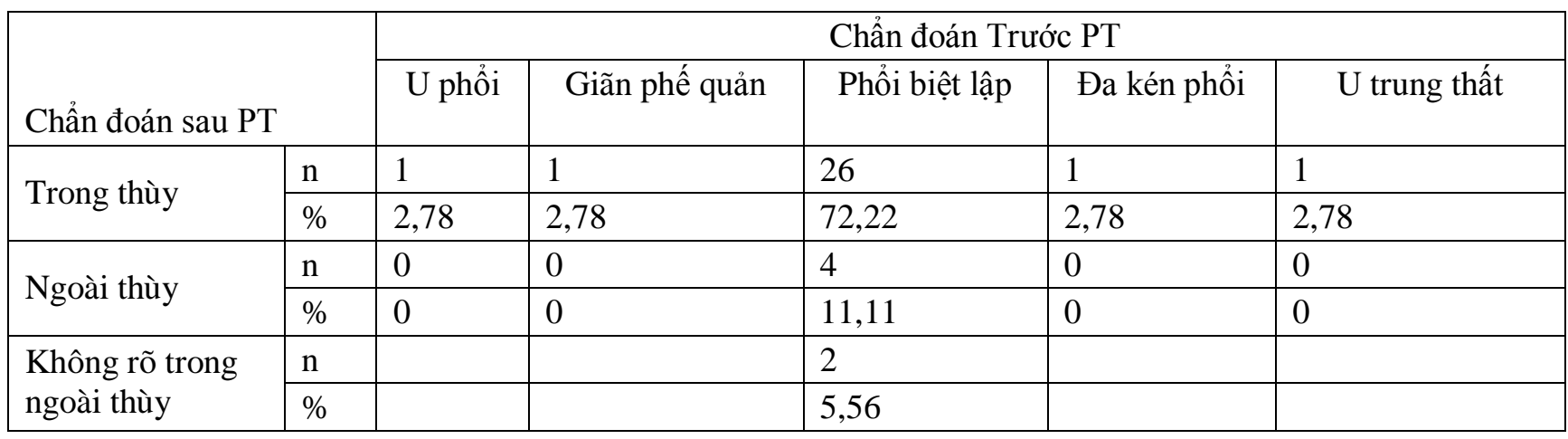

\subsection{Tai biến và biến chứng}

Bảng 3.5: Tai biến và biến chứng

\begin{tabular}{|c|c|c|c|c|c|c|}
\hline $\begin{array}{c}\text { Biến } \\
\text { chứng }\end{array}$ & $\begin{array}{c}\text { Không biến } \\
\text { chứng }\end{array}$ & $\begin{array}{c}\text { Chảy máu } \\
\text { au mổ }\end{array}$ & $\begin{array}{c}\text { Viêm mủ } \\
\text { màng phổi }\end{array}$ & $\begin{array}{c}\text { Rò khí } \\
\text { kéo dài }\end{array}$ & $\begin{array}{c}\text { Xẹp phổi } \\
\text { sau mổ }\end{array}$ & $\begin{array}{c}\text { Rò thực quản } \\
\text { sau mổ }\end{array}$ \\
\hline $\mathbf{n}$ & 29 & 2 & 1 & 1 & 2 & 1 \\
\hline$\%$ & 80,56 & 5,56 & 2,78 & 2,78 & 5,56 & 2,78 \\
\hline
\end{tabular}

3.4. Kết quả ra viện: $100 \%$ ổn địch trước khi ra viện, XQ phổi nở tốt, còn số ít có viêm dày màng phổi, không có trường hợp nào biến chứng nặng hay tử vong sau mổ.

\section{BÀN LUẬN}

4.1 Tuổi, giới: Nam/Nũ: 1/1,77. Tuổi thấp nhất:11,Tuổi cao nhất: 62 , Tuổi trung bình: 33,19 \pm 13 tuổi; nhóm tuổi $<16$ tuổi: 2 trường hợp, $>=16$ tuổi 34 trường hợp, kết quả tương tự với tác giả Phạm Minh Ánh[1] nghiên cứu 14 trường hợp phổi biệt lập thấy nam/ nữ: $1 / 1.8$; tuổi trung bình $36,36 \pm 17,72$. không có trường hợp nào có trẻ dưới 16 tuồi. Về giới tính tỷ lệ nam/nữ trong kết quả của chúng tôi ngược so một số tác giả trên thê giới: Theo Dirk Van Raemdonck [2] ở nhóm tuổi $<15$ tuổi: tuổi thấp nhất:0, cao nhất: 14 , tuổi trung binh: $3 \pm 5$; nhóm $>15$ tuổi có 15 trường hợp, tuổi trung bình chẩn đoán bệnh là $33 \pm 13$ tuổi, tuối trung bình trung cả 2 nhóm: $19 \pm 18$, nam nhiều hơn nữ: 18 nam/10 nữ, Gezer $\mathrm{S}$. et al[2] nam/ nữ: 1,7/1. Theo Halkic[4] phổi biệt lập trong thùy nam: nữ $=1: 1$, thường chẩn đoán sau tuồi 20, trong khi phổi biệt lập ngoài thùy nam: nữ $=4: 1$. và tuổi chẩn đoán thường sớm sau sinh hoặc thiếu niên. Như vậy, dị tật này không nên bị lãng quên khi có triệu chứng sớm về hô hấp.

4.2 Tiền sủ bệnh hô hấp: (Bảng 3.1)15 trường hợp không có tiền sử bệnh hô hấp. 21 trường hợp có tiền sử chẩn đoán và điều trị các bệnh hô hâp khác nhau như: viêm phổi, lao phồi, apxe phổi, viêm hô hấp tái diễn, ho máu... Tại Việt nam chưa có báo cáo nào về tiền sử chẩn đoán các bệnh hô hấp trước đó, theo một số tác giả nước ngoài các tác giả Dirk Van Raemdonck[2], xếp vào nhóm dấu hiệu và triệu chứng của bệnh như: bệnh nhân có viêm phổi, nhiễm trùng mạn tính tái phát, ho máu đó là dấu hiệu gợi ý đến phổi biệt lập, do đó ngay từ khám tuyến đầu ngoài các bệnh hô hấp thường gặp cũng cần cảnh giác với phổi biệt lập có biến chứng.

4.3 Triệu chứng lâm sàng: (Bảng 3.1)1 trường hợp không có triệu chứng, phát hiện bệnh qua đi khám sức khỏe định kỳ. Triệu chứng cơ năng gặp chủ yếu ho, đau ngực, sốt, khó thở. Khám thực thể ngực có 21 trường hợp có triệu chứng ở phổi: chủ yểu có tình trạng viêm nhiễm tại phổi, 6 trường hợp có hội chứng ba giảm. Trong nghiên cứu của chúng tôi triệu chứng lâm sàng cũng tương tự như trong báo cáo của tác giả Halkic[4] ho, sốt đau ngực, khó thở là các triệu chứng chủ yếu. Như vậy hầu hết các trường hợp không có dấu hiệu lâm sàng biểu hiện sớm mà chỉ khi có biến chứng mới biểu hiện lâm sàng và đi khám với các dấu hiệu: ho, sốt, đau ngực, khó thở, ho máu, tình trạng viêm phồi tái diễn..,vì vậy chúng ta không nên bỏ quên dị tật về phổi này để tránh điều trị nội khoa kéo dài dẫn đến sự chậm trễ trong chẩn đoán và can thiệp sớm.

4.4 Cân lâm sàng: Chụp XQ ngực thường quy: $100 \%$ tổn thương nằm ở thùy dưới, phổi trái chiếm ưu thế (23/36 trương hợp). So với các tác giả khác, tổn thương cũng chủ yếu thùy dưới và ưu thế ở phổi trái. Hình ảnh chủ yếu 3 dang tổn thương: dạnh u, kén khí, viêm. Tổn thương giống như các bệnh thông thường khác nên dễ dẫn đến chẩn đoán nhầm. So nghiên cứu của tác giả Gezer $\mathrm{S}$. et al [2]: 23 trường hợp kén khí, 9 
trường hợp dạng khối không chứa khí, cũng chủ yếu ở thùy dưới. Như vậy hình ảnh XQ có tính gợi ý đến phổi biệt lập chứ không khẳng định là phổi biệt lập, và cần chụp $C T$ scanner ngực để chẩn đoán chính xác và có thái độ điều trị phù hợp. Hình ảnh trên cắt lớp vi tính ngực (Bảng 3.2) tổn thượng dạng kén khí, chiếm nhiều với $15(41,67 \%)$ trường hợp, $9(25 \%)$ trường hợp nang dịch, $6(16,67 \%)$ trường hợp dạng u phổi, $6(16,67 \%)$ trường hợp dạng viêm phổi. Mạch máu nhìn rõ trên $\mathrm{CT}$ scanner ngực 32 trường hợp, trong đó nguyên ủy từ ĐMC ngực 22/32 trường hợp, từ ĐMC bụng $8 / 32$ trường hợp, từ động mạch thân tạng $2 / 32$ trường hợp, 4 trường hợp không mô tả mạch bất thường. Như vậy, nhờ sự phát triển của $\mathrm{CT}$ Scanner giúp chẩn đoán phổi biệt lập được dễ dàng và không cần thiết làm chụp mạch chẩn đoán. Hình ảnh trên CTScanner cũng như XQ thường quy, có tổn thương giống các bệnh lý khác của phổi, nhưng khi có tiêm thuốc cản quang và dựng hình mạch máu có tính chất quyết định chẩn đoán và giúp phẫu thuật viên cảnh giác với các mạch máu bất thường (số lượng, kích thước, nguyên ủy) và tránh được các tai biến đáng tiếc trong phẫu thuật khi không biết trước các mạch bất thường này. Kết quả nghiên cứu của chúng tôi cũng tương tự với kết quả nghiên cứu của Hong-sheng Lui, et al[6] nghiên cứu 47 trường hợp phổi biệt lập trong thùy thấy hình ảnh trên phim chụp $\mathrm{CT}$ : dạng khối 19/47 trường hợp, dạng nang, gồm cả loại có mức dịch khí 15/47 trường hợp, dạng giãn phế quản hơn 12/47 trường hợp, 1 trường hợp tràn dịch màng phổi và phát hiện mạch máu bất thường cấp máu cho phổi giúp chẩn đoán đúng trước mổ 35/47 (74,47\%) trường hợp phổi biệt lập, và động mạch cấp máu cũng chủ yếu từ ĐMC ngực.

4.5. Chẩn đoán trước mổ và sau mổ: (Bảng 3.4) Chẩn đoán đúng trước mổ $32(88,89 \%)$ trường hợp, $4(11,11 \%)$ trường hợp chẩn đoán nhầm bệnh khác: $u$ phổi, giãn phế quản, đa kén phổi, u trung thất, so với kết quả sau mổ có 30 trường hợp chẩn đoán phổi biệt lập trong thùy, 4 trường hợp ngoài thùy, 2 trường hợp không xác địch vị trí trong hay ngoài thùy. Như vậy nhờ có chụp CTscanner độ phân giải cao, dựng hình mạch máu mà việc chẩn đoán chính xác trước mổ có tỷ lệ cao, mặc dù có 4 trường hợp $(11,11 \%)$ chẩn đoán nhầm sang các bệnh khác. Trong phẫu thuật do viêm dính lâu ngày và tái diễn nên trong mổ có số ít trường hợp không phân định được loại phổi biệt lập trong hay ngoài thùy. So với kết quả nghiên cứu của Hongsheng Lui, et al[6] chẩn đoán đúng trước mổ còn hạn chế 35/47(74,47\%) trường hợp phổi biệt lập, 12 trường hợp $(25,53 \%)$ còn lại chẩn đoán nhầm sang các bệnh lý khác, so sánh 2 tỷ lệ có sự khác biệt có ý nghĩa thống kê với $\mathrm{p}<0,05$. Tuy nhiên do quá trình viêm nhiễm trước đó đã làm thay đổi danh giới giữa phần phổi lành với phần phổi biệt lập dẫn đến việc phân loại trong mổ trong nghiên cứu của chúng tôi cũng gặp khó khăn khi phân loại phổi biệt lập trong hay ngoài thùy.

4.6 Điều trị: Peter B. Kestenholz[8] nghiên cứu phẫu thuật nội soi trong điều trị phổi biệt mặc dù khó khăn do viêm nhiễm trước đó nhưng thời gian phẫu thuật trung bình 133 phút, nhanh 45 phút, lâu nhất 270 phút. Chúng tôi mổ mở 36 trường hợp thời gian mổ trung bình 195.6 phút (Bảng 3.3), tối đa 365 phút, tối thiểu 90 phút, trong đó phổi phải 13 trường hợp, phổi trái 23 trường hợp, $34(94,44 \%)$ cắt thùy phối chứa phổi biệt lập, $1(2,78 \%)$ trường hợp cắt phân thùy phổi, $1(2,78 \%)$ trường hợp cắt nguyên phần phổi biệt lập, động mạch bất thường: chủ ngực 23 trường hợp, chủ bụng 12 trường hợp, 1 trường hợp có cả nhánh của chủ ngực và chủ bụng, số lượng mạch bất thường: 1 mạch 27 trường hợp, hơn 1 mạch bất thường có 9 trường hợp. kích thước mạch chủ yếu $<10 \mathrm{~mm}$.. Không biến chứng trong mổ. Các bệnh nhân không biến chứng như rò khí, viêm mủ màng phổi, rò tiêu hóa thì thời gian dẫn lưu trung bình 8 ngày. Thời gian nằm viện trung bình 29 ngày. Tối thiểu 11 ngày, tối đa 56 ngày. Thời gian nằm viện sau mổ trung bình 15 ngày, không có biển chứng trong mổ. Thời gian phẫu thuật kéo dài do tình trạng phổi viêm lâu ngày nên dính vào các thành phần khác trong lồng ngực làm phẫu thuật gặp nhiều khó khăn và kéo dài đặc biệt vùng có mạch máu bất thường nên việc bộc lộ mạch máu khó khăn và nguy hiểm, tuy nhiên với kinh nhiệm và thận trọng trong phẫu thuật. Có 4 trường hợp không mô tả mạch bất thường trên CTScanner ngực, nhưng không có tai biến đáng tiếc nào liên quan tới các mạch bất thường này. Thời gian nằm viện sau mổ kéo dài so các tác giả khác do tình trạng viềm nhiễm trước mổ, diện viêm dính thường rộng, thời gian mổ kéo dài, sau mổ nhiều nguy cơ nhiễm trùng. Để hạn chế các nguy cơ và rút ngắn thời gian nằm viện sau mổ nên chẩn đoán và phẫu thuật sớm khi phổi biệt lập chưa có biến chứng nhiễm trùng tái diễn. Theo tác giả: Savic $\mathrm{B}$ et al[7], nghiên cứu 540 trường hợp phôi biệt lập, phổi biệt lập trong thùy chiếm $75 \%$, ngoài thùy dưới $25 \%$, vị trí chủ yếu thùy dưới của phổi. Động mạch cấp máu cho phần phổi biệt lập này là chủ yếu từ ĐMC ngực và chủ bụng, kích thước động mạch trung bình 6,3-6,6mm. Điều trị cắt thùy phổi trên nhóm $\mathrm{PBL}$ trong thùy $71,5 \%$, cắt 1 phần thùy $13 \%$, cắt phần phổi biệt lập $3,5 \%$, phổi biệt lập ngoài thùy chủ yếu cắt nguyên phần phổi biệt lập. Theo Dirk Van Raemdonck[2], ở 15 trường hợp người trưởng thành thì tỷ lệ cắt thùy phổi là chủ yếu do tình trạng viêm nhiễm trước đó, nhưng ở nhóm trẻ <=16 tuổi thì tỷ lệ cắt thùy có thấp 
hơn 1/2 lần. Theo Jolanta hauer[5], nghiên cứu 23 trường hợp phổi biệt lập cũng cho kết quả tương tự chủ yếu cắt thùy phổi 14/20 trường hợp. Nguyên ủy động mạch bất thường chủ yếu từ ĐMC ngực 17/23 và chủ bụng 6/23 trường hợp, số lượng mạch bất thường chủ yếu là 1 , chỉ có 5 trường hợp có nhiều hơn 1 động mạch bất thường. Như vậy, việc chẩn đoán và điểu trị phẫu thuật sớm có ý nghĩa khi phổi biệt lập chưa có biến chứng, chưa có viêm nhiễm tái diễn làm mất ranh giới giữa phần phổi lành và phần dị tật, tránh tỷ lệ cắt thùy phổi tăng cao trong khi chỉ cần cắt bỏ phần phổi chứa phổi biệt lập trong thùy hoặc cắt bỏ phần phổi biệt lập ngoài thùy.

4.7 Biến chứng: 29 trường hợp không có biến chứng sau mổ. 2/36 trường hợp chảy máu sau mổ, $2 / 36$ trường hợp xẹp phổi sau mổ, $1 / 36$ trường hợp rò khí và $1 / 36$ trường hợp viêm mủ màng phổi, $1 / 36$ trường hợp rò thực quản sau mổ, các biến chứng thường nhẹ không có trường hợp nào nặng hoặc tử vong khi ra viện, không có trường hợp nào tai biến liên quan tới mạch máu bất thường, các trường hợp biến chứng được điều trị kéo dài và hết biến chứng. Theo kết quả nghiên cứu của một số tác giả thì tỷ lệ chảy máu trong mổ liên quan tới động mạch bất thường là tương đối cao so với nghiên cứu của chúng tôi: Jolanta hauer $\mathrm{N}$, [5] 8/23 trường hợp chảy máu, 1 trường hợp khó thở sau mổ, 1 trường hợp liệt hoành. Halkic[4]: 3 trường hợp chảy máu trong mổ, 2 trường hợp rò phế quản, 2 trường hợp nhiễm trùng màng phôi, 1 trường hợp chảy máu ổ bụng sau cắt động mạch bất thường.

Ngay cả trường hợp đặc biệt rò thực quản sau mổ, bệnh nhân sau mổ phải thực hiện thêm nhiều thủ thuật và phẫu thuật hỗ trợ, thời gian nằm viện kéo dài $>375$ ngày. Có lẽ đây là trường hợp phổi biệt lập có phối hợp với rò đường tiêu hóa hoặc do người bệnh bị viêm phối tái diễn nhiều lần làm thay đổi giải phẩu khi phẫu thuật cũng khó tránh được tổn thương vào thực quản. Nhiều tác giả trên thế giới cũng đã báo cáo về các nghiên cứu phồi biệt lập có phối hợp với các dị tật bẩm sinh khác như: Savic B[7] phổi biệt lập có kèm theo các dị dạng trong đó rò thực quản phế quản trong phổi biệt lập ngoài thùy, nang thực quản phế quản trong phổi biệt lập trong thùy, ngoài ra còn có các dị dạng cơ hoành, hệ xương, tim mạch..Để hạn chế biến chứng này, khi chẩn đoán phổi biệt lập nên chủ động làm thêm chẩn đoán các dị dạng kèm theo đặc biệt của đường tiêu hóa: Soi, chụp thực quản dạ dày tránh được việc bỏ sót thương tổn phối hợp trong phẫu thuật.

4.8 Kết quả trước khi ra viện: $100 \%$ ổn định trước khi ra viện, XQ phổi nở tốt, còn số ít có viêm dày màng phổi, không có trường hợp nào biến chứng nặng hay tử vong sau mổ.

\section{KẾT LUẬN}

Phổi biệt lập là dị tật bẩm sinh, cần chẩn đoán và phẫu thuật sớm tránh biến chứng và di chứng. Tỷ lệ nam/ nữ: $1 / 1,77$. Tuổi chẩn đoán thường muộn, trung bình 33,19 \pm 13 tuổi, phần lớn có dấu hiệu gợi ý đến phổi biệt lập: các bệnh hô hấp tái diễn, đau ngực và ho, sốt, khó thở, hình ảnh XQ ngực thường quy chủ yếu với 3 dạng tổn thương: dạng u, kén khí, viêm. Chẩn đoán xác định dựa trên CTScanner ngực có dựng hình mạch máu phát hiện mạch bất thường từ hệ ĐMC cấp máu cho phân phổi tổn thương. Điều trị phẫu thuật chủ yếu cắt thùy phổi 34/ 36 trường hợp, 1 trường hợp cắt phần phổi chứa phổi biệt lập, 1 trường hợp cắt phồi

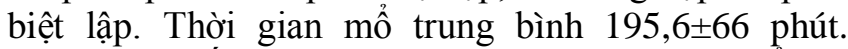
Không có biến chứng chảy máu trong và sau mổ iên quan tới mạch bất thường. Biến chứng sau mổ thường nhẹ, đặc biệt có 1 trường hợp rò thực quản. Thời gian nằm viện sau phẫu thuật khi không có biến chứng trung bình $15,84 \pm 8,18$ ngày. $100 \%$ ra viện với tình trạng ổn định, không có tử vong sau mổ.

\section{TÀI LIỆU THAM KHẢO}

1. Phạm Minh Ánh.(2010) "Phổi biệt lập: nhân hồi cứu 14 trường hợp tại Bệnh viện Chợ Rẫy." (Hội phẫu thuật tim mạch và lồng ngực Việt Nam (phauthuattim.org.vn).

2. Van Raemdonck, D., et al., Pulmonary sequestration: a comparison between pediatric and adult patients. Eur J Cardiothorac Surg, 2001. 19(4): p. 388-95.

3. Gezer S. et al (2007): "Pulmonary sequestration: A single-institutional series composed of 27 cases"; Journal of Thoracic and Cardiovascular Surgery; Volume 133; pp. 955-959

4. Halkic N. et al (1998): "Pulmonary sequestration: a review of 26 cases".

European Journal of Cardio-thoracic Surgery; 14; pp. 127-133.

5. Hauer, J., et al., Pulmonary Sequestration-Analysis of Diagnostic and Therapeutic Difficulties. Polish Journal of Surgery, 2007. 79(1): p. 24-28.

6. Liu, H.-s., et al., Surgical treatment of intralobar pulmonary sequestration. Chinese Medical Sciences Journal, 2010. 25(1): p. 53-56.

7. Savic B, et al. (1979): "Lung sequestration: report of seven cases and review of 540 published cases". Thorax; 34: 96.

8. Kestenholz, P.B., et al., Thoracoscopic treatment of pulmonary sequestration. Eur J Cardiothorac Surg, 2006. 29(5): p. 815-8. 